\title{
DOKTORA EĞİTİMİNDEKİ ÖĞRENCİLERİN KLASİK VE MODERN YÖNTEM İLE YAPTIKLARI KÖK KANAL TEDAVİLERİNİN KALİTESİNİN RADYOGRAFİK OLARAK DEĞERLENDİRİLMESİ
} 4

\section{RADIOGRAPHIC EVALUATION OF THE QUALITY OF ROOT CANAL TREATMENTS PERFORMED BY PHD STUDENTS WITH CLASSICAL AND MODERN METHODS ${ }^{*}$}

\author{
Dr. Öğr. Üyesi Dursun Ali şİRİN*
}

Dursun Ali Şirin: ORCID ID: 0000-0001-7159-1977

\section{öz}

Amaç: Bu çalışmanın amacı doktora öğrencilerinin klasik ve modern yöntemlere göre yaptıkları kök kanal tedavilerinin kalitesini radyografik başarı kriterlerine göre belirlemek ve kök kanal tedavisi kalitesinin arttırımasına katkı sağlamaktır.

Gereç ve Yöntem: Bu çalışma Sağlık Bilimleri Üniversitesi, Diş Hekimliği Fakültesi, Endodonti Anabilim Dalı doktora öğrencileri tarafından, 228' i klasik ( paslanmaz çelik el eğeleri ) ve 273'ü modern ( Ni-Ti döner aletler ) yöntemle yapılan toplam 501 dişin kök kanal tedavilerinin kalitesinin radyografik olarak değerlendirilmesiyle yapıldı. Değerlendirme, kök kanal dolgusunun homojenitesi ve kök kanal dolgusunun apikalde sonlandığı nokta ile radyografik apeks arasındaki mesafeye göre yapıldı. Değerlendirme de doldurulmuş kök kanalının kalitesine göre 0 ile 3 arası puanlama kriterleri içeren, Radyografik Kalite Puanlaması (RKP) sistemi kullanıldı. Buna göre 2'den az puanlar başarısız, 2 ve üzeri puanlar başarılı kabul edildi.

Bulgular: Klasik ve modern yöntemin kullanıldığ tüm diş gruplarında, RKP skorları arasında istatistiksel olarak anlamlı bir korelasyon yoktu (Spearman r: $-0.03617,95 \%$ güven aralığı: -0.1634 ile $0.09224, \mathrm{P}=0.5700$ ). Kök kanal tedavi yöntemleri, radyografik başarı skorları açısından incelendiğinde; alt-üst anterior ve alt premolar gruplarında fark yok iken, üst premolar, üst molar ve alt molar gruplarında klasik yönteme kıyasla modern yöntemde daha yüksek RKP skoru elde edildi (sırasıyla, üst premolar: $2.22 \pm 0.91$ ve $2.71 \pm 0.52 \mathrm{P}=0.0261$, üst molar: $2.09 \pm 1.05$ ve $2.61 \pm 0.65 \mathrm{P}=0.0061$, alt molar: $2.13 \pm 0.96$ ve $2.68 \pm 0.63 \mathrm{P}=0.0008$ ).

Sonuç: Döner aletlerle yapılan kök kanal tedavilerinin radyografik kalitesi, paslanmaz çelik el eğeleri ile yapılanlara göre daha başarılı bulunmuştur. Molar dişlerdeki tedavi başarısının artırılması için bu dişlere yönelik eğitimlere ağırlık verilmelidir.

Anahtar kelimeler: Endodonti doktora eğitimi, kök kanal tedavisi kalitesi, radyografik değerlendirme, Ni-Ti döner eğeler, paslanmaz çelik eğeler

\section{ABSTRACT}

Aim: The aim of this study is to determine the quality of root canal treatments performed by PhD students with classical and modern methods according to radiographic success criteria and to contribute to the improvement of root canal treatment quality.

Material and Methods: This study was carried out by University of Health Sciences, Faculty of Hamidiye Dentistry, Department of Endodontics, with a total of 228 classical (stainless steel hand files) and 273 modern (Ni-Ti rotary instruments) method. The evaluation was based on the homogeneity of the root canal filling and the distance between the point where the root canal filling ends at the apical and the radiographic apex. RQS (Radiographic Quality Scoring) was used to evaluate the quality of root canal treatments, which included scoring criteria between 0 and 3 according to the quality of the filled channel. According to this, scores less than 2 were unsuccessful, scores 2 and above were considered successful.

Results: There was no statistically significant correlation between (RQS) scores in all tooth groups using the classical and modern method (Spearman r: $-0.03617,95 \%$ confidence interval: -0.1634 to $0.09224, P=0.5700$ ). When root canal treatment methods are examined in terms of treatment success scores; In the upper premolar, upper molar and lower molar groups, higher RQS score was obtained in the modern method compared to the classical method (upper premolar: $2.22 \pm 0.91$ and $2.71 \pm 0.52 \mathrm{P}=0.0261$, upper molar: $2.09 \pm 1.05$ and $2.61 \pm 0.65 \mathrm{P}=0.0061$, lower molar: $2.13 \pm 0.96$ and $2.68 \pm 0.63 \mathrm{P}=$ $0.0008)$.

Conclusions: The radiographic quality of root canal treatments made with rotary instruments has been found to be more successful than those made with stainless steel hand files. In order to increase the success of treatment in molars, training for these teeth should be increased.

Key Words: PhD education of endodontics, quality of root canal treatment, radiographics evaluations, Ni-Ti rotary instruments, stainless steel hand files

* Sağlık Bilimleri Üniversitesi, Hamidiye Diș Hekimliği Fakültesi Endodondi AD.

Kaynakça Bilgisi: Şirin DA. Doktora eğitimindeki öğrencilerin klasik ve modern yöntem ile yaptıkları kök kanal tedavilerinin kalitesinin radyografik olarak değerlendirilmesi. Atatürk Üniv Diş Hek Fak Derg 2021; 31: 528-34.

Citation Information: Sirin DA. Radiographic evaluation of the quality of root canal treatments performed by phD students with classical and modern methods. J Dent Fac Atatürk Uni 2021; 31: 528-34. 


\section{GİRİŞ}

Kök kanal tedavisi, doğru teşhis ile beraber hastalıklı diş pulpasının çıkartılarak kanalların şekillendirilmesi, temizlenmesi ve son olarak koronalden apikale kadar üç boyutlu olarak biyouyumlu kanal dolgu maddeleriyle homojen bir şekilde doldurulmasını kapsamaktadır. ${ }^{1,2}$ Kanal tedavisindeki bütün aşamalar önemli olsa da, kök kanal dolgusunun mikroorganizmaların çoğalmasını ve apikal dokulara geçişini engelleyecek şekilde sızdırmaz olması kanal tedavisinin başarısı açısından oldukça önemlidir. ${ }^{3}$ Eksik yapılan kök kanal dolgusu sonucunda, kök kanalı içinde ve periapikal bölgede canlı kalan mikroorganizmaların çoğalmasına bağlı olarak tekrar enfeksiyon gelişebilir. ${ }^{4}$

Kök kanal dolgusunun kalitesi ile tedavi sonrasında gelişen apikal periodontitis arasında yakın bir ilişki olduğu bildirilmişdir. ${ }^{5,6}$ Kök kanal tedavisi sonrası, kök kanal dolgusunun sonlandığı nokta ile apeks arasındaki mesafenin $2 \mathrm{~mm}$ den daha kısa olduğu vakalarda, kanal dolgusunun yetersiz ve apeks ile arasındaki doldurulmamış mesafenin $2 \mathrm{~mm}$ den fazla olduğu veya taşkın dolgu olduğu vakalara göre daha az apikal radyolusensi görüldüğü belirtilmiştir.7,8

Kök kanal dolgusu kalitesi tedavi sonrası alınan radyografilerde kanal dolgusunun yoğunluğu (homojenliği) ve radyografik apekse olan uzaklığı baz alınarak değerlendirilebilmektedir. ${ }^{9}$ Fakat konvansiyonel radyografiler bize iki boyutlu bir inceleme olanağı sağladığı için üçüncü boyuttaki kanal dolgusunun durumu izlenememektedir. Kanal dolgularının kalitesinin izlenmesinde en güvenilir yöntem bilgisayarlı tomografi olmasına rağmen yüksek maliyet ve yüksek radyasyon dozu nedeniyle her vakada rutin kullanımı çok yaygın değildir. 10,11

Diş hekimliğinde kanal tedavisi uygulamaları diş hekimlerinin en çok zorlandığı tedaviler arasında bulunmaktadır. ${ }^{5,12} \mathrm{Bu}$ yüzden hem stajyer öğrencilerin hem de endodonti alanında uzmanlık ve doktora yapan hekimlerin bilgi ve becerilerinin geliştirilmesi için iyi bir eğitim verilmesi gerekmektedir. Teorik derslerin uygulama eğitimleriyle desteklenmesi ve mümkün olduğu kadar çok uygulama yapılması pratik yeteneklerini ve tecrübelerini arttıracaktır.

Bu çalışmada, doktora eğitimi alan öğrencilerin aldığı eğitimlerin ve yaptığı endodontik tedavilerin değerlendirilmesi ve varsa eksikliklerin giderilmesi ile beraber aynı zamanda klasik yöntemle el eğeleri ve modern yöntemle döner aletlerle yapılan endodontik tedavilerinin kalitesinin karşılaştırılması amaçlanmıştır. Sıfır hipotezi klasik yöntemle el eğeleri ve modern yöntemle döner aletlerle yapılan endodontik tedaviler arasında kaliteleri bakımından fark olmamasıydı.

\section{GEREÇ VE YÖNTEM}

Bu çalışma, Sağlık Bilimleri Üniversitesi, Hamidiye Diş Hekimliği Fakültesi Endodonti Anabilim Dalında doktora yapan 4 (dört) hekim tarafından, Ocak 2019 ile Haziran 2019 tarihleri arasında, 228' i klasik yöntem (Paslanmaz çelik el eğeleri ile Step-back kanal genişletme yöntemi ve lateral kondensasyon kök kanal dolgu yöntemi uygulanarak ) ve 273'ü modern yöntem (Endodontik motorla kullanılan Ni-Ti döner eğelerle ve bu eğelerle birebir uyumlu açılı guta-perka konlar kullanılarak uygulanan tek kon kök kanal dolgu yöntemi) uygulanan toplam 501 dişin kök kanal tedavilerinin kalitesinin radyografik olarak değerlendirilmesiyle yapıldı. Çalışmamız doktora öğrencilerinin, pulpa ve periapikal doku hastalıkları teşhis ve tedavisi, kök kanal genişletme yöntemleri, Endodonti de irigasyon ve obturasyon gibi zorunlu temel derslerini teorik ve uygulamalı olarak aldıktan sonra başlamıştır. Doktora öğrencilerine hasta verilirken randomizasyona dikkat edilmiş, ön-arka grup dişler ve klasik-modern yöntem seçiminde eşit dağılım yapılmış olup hepsinin bütün gruplarda çalışması sağlandı. Bu çalışmada, tüm hastalara bilgilendirme ve onam formları imzalatılmış, hastane veri ve radyografik görüntüleri kullanma izinleri ve etik onay (Hamidiye Bilimsel Araştırmalar Etik Kurulu, kayıt no: 20/226) alınmış olup, Helsinki Deklerasyonu 2008 prensiplerine uygun olarak yapılmıştır.

Dahil edilme kriterleri:

Başlangıç tanı radyografisi ve kanal dolgusu bitim radyografisi olan dişlerden radyografide köklerin tamamının görünmesi, diş köklerin ve kanal dolgusunun net olarak izlenebilir olması.

Çalışmaya dahil edilen 501 dişin, 249 (\% 49,7) tanesi üst çene, $252(\% 50,3)$ tanesi alt çene bölgesi dişleriydi. Dişlerin bölgelere (anterior, premolar, molar) ve yöntemlere (klasik-modern) dağılımları tablo 1'de gösterilmektedir. Medikal ve dental hikayeleri alınıp, klinik ve radyografik muayeneleri yapılan hastalardan kök kanal tedavisi yapılacak dişi belirlenerek teşhis konuldu. Teşhisi konulan dişlere lokal anestezi yapıldıktan sonra, rubber-dam (Optradam Plus, Ivoclar Vivadent, Liechtenstein) uygulaması yapılıp endodontik giriş kaviteleri açıldı. Daha sonra, ISO \#6-15 arası Ktipi el eğeleri ile kök kanallarına ilk giriş yapıldı. Çalışma uzunluğu apeks bulucu (VDW GmbH, Münih, Almanya) ve radyografiler yardımıyla, fizyolojik apikal foramende olacak şekilde belirlendi. Tüm radyogra- 
filer, X-ray cihazı (Evostyle EX; New Life Radiology, İtalya) ile $70 \mathrm{kV}, 8 \mathrm{~mA}$ ayarında alındı ve radyografik görüntüleme sistemi olan (RVG) (Suni Medical Imaging, Kaliforniya, ABD) üzerinden incelendi.

Paslanmaz çelik el eğeleri kullanılan grupta step-back kanal şekillendirme yöntemi uygulanmıştır. Diş köklerinin koronal üçlü bölümü gates-glidden frezler (VDW GmbH, Münih, Almanya) ile genişletildikten sonra ISO $\mathrm{K}$ ve $\mathrm{H}$ tipi eğeler ile orta ve apikal üçlü genişletilmiştir. Her eğeleme işleminden sonra kök kanalları $2 \mathrm{ml} \% 5^{\prime}$ lik NaOCl (Wizard, Rehber Kimya, İstanbul, Türkiye) ile yıkanmıştır. Kök kanallarının şekillendirilmesi tamamlandıktan sonra her kanala irigasyon protokolü sırasıyla; $4 \mathrm{ml} \% 5^{\prime}$ lik NaOCl, $2 \mathrm{ml}$ distile su, 2 ml \%17 EDTA (Wizard, Rehber Kimya, İstanbul, Türkiye), $2 \mathrm{ml}$ distile su ve $2 \mathrm{ml} \% 2$ 'lik Klorheksidin Glukonat (Mıcrovem, Altun Medikal, İstanbul, Türkiye) uygulandı. Vital pulpalı dişlerin kanal dolgusu aynı seansta tamamlanırken nekrotik ve apikal periodontitisli dişlerin kanallarına kalsiyum hidroksit (Kalsin, Aktu Ticaret, İzmir, Türkiye) uygulanarak iki hafta sonrasına randevu verildi. Randevu tarihinde semptomsuz dişlerin kök kanalları dolduruldu. Semptomu tam geçmemiş olan dişlere ikinci kez kalsiyum hidroksit uygulanarak tekrar iki hafta daha bekletildi. Kalsiyum hidroksitin kanallardan uzaklaştırıması için ana apikal eğe [Master Apical File (MAF)] ile eğeleme yapılarak tekrar irigasyon protokolü uygulandı. Kanalların doldurulması lateral kondensasyon yöntemine göre, güta perka (DiaDent, Güney Kore) ve epoksi rezin esası kök kanal dolgu patı Endoplus (President Dental $\mathrm{GmbH}$, Münih, Almanya) ile yapılmışır.

Döner alet kullanılarak kök kanal tedavisi yapılan gruplarda ise kanal şekillendirmesi, kendinden apexlocator' lü endodontik tork kontrollü motor olan VDW Gold Reciproc (VDW GmbH, Münih, Almanya) kullanılarak 'reciproc all' modunda yine kendi orijinal VDW Resiproc Ni-Ti eğeleri kullanılarak yapıldı. Benzer yıkama ve smear tabakası uzaklaştırma protokolü tüm dişlerde uygulandı. Seans arası kalsiyum hidroksit patı ve geçici dolgu maddesi (Cavit; 3M ESPE, Seefeld, Almanya) ile kapatılarak iki hafta beklendi. Çift seanslı işlemlerin ikinci seansında kalsiyum hidroksit, MAF eğe ve irigasyon yapılarak uzaklaştırdıktan sonra, kağıt konlar ile kurulandı. Resiprokal hareket ederek şekillendirme yapan eğelerle uyumlu kendi açılı güta perkaları kullanılarak tek kon tekniği ile Endoplus kanal dolgu patı kullanılarak kanal dolguları tamamlandı. Kök kanal şeklinin dairesel olmadığı ve tek kon açılı güta perkanın kanala tam uyum sağlamadığı durumlarda spreader ile kontrol edilerek 0.02 açlı güta perka konlarla lateral kondensasyon yapıldı.

Değerlendirme retrospektif olarak bitim periapikal radyografilerleri üzerinden bir endodonti uzmanı ve 15 yıllık meslek deneyimi olan tecrübeli bir doktora öğrencisi hekim tarafından aynı değerlendirme kriterlerine göre farklı zamanlarda iki kere yapıldı. Deneyimli olan doktora öğrencisi yanlııktan kaçınmak için tedavilere katımayıp sadece değerlendirmeye katılıışır. Diğer 3 doktora öğrencilerinin deneyimleri birbirine yakındır. Elde edilen verilerde gözlemci içi ve gözlemciler arası uyum araştırıldı. Hem gözlemci içi hem gözlemciler arası neredeyse mükemmel düzeyde uyum belirlendi (Kappa değeri 0,920).

Değerlendirme, kök kanal dolgusunun homojenitesi (lateral kondensasyon) ve kök kanal dolgusunun apikalde sonlandığı nokta ile radyografik apeks arasındaki mesafeye göre yapıldı. ${ }^{13,14}$ Değerlendirme de doldurulmuş kanalın kalitesine göre 0 ile 3 arası puanlama içeren, kök kanal tedavisi radyografik kalite puanlaması (RKP) sistemi kullanıldı (Tablo 1).

Tablo 1. Kök kanal tedavisi Radyografik Kalite Puanlaması (RKP) sistemi

\begin{tabular}{|c|c|c|}
\hline RKP & $\begin{array}{c}\text { Homojenite } \\
\text { (lateral kondensasyon) }\end{array}$ & Apikal uzunluk \\
\hline $\mathbf{0}$ & $\begin{array}{c}\text { KÖTÜ } \\
\text { - Guta-perka ile kök kanal duvarı } \\
\text { arasında belirgin boşluk } \\
\text { - Homojen olmayan kök kanal } \\
\text { dolgusu ve dolgu içinde birden } \\
\text { fazla boşluk } \\
\end{array}$ & $\begin{array}{c}\text { KÖTÜ } \\
\text { - Radyografik apeks ile guta- } \\
\text { perka'nın sonlandığı nokta } \\
\text { arasında( } \geq 2 \mathrm{~mm}) \text { mesafe } \\
\text { - } \quad \text { Apikalden taşmış kök kanal } \\
\text { dolgusu } \\
\end{array}$ \\
\hline 1 & \begin{tabular}{|c|} 
YETERLİ \\
- Guta-perka ile kök kanal duvarı \\
arasında kabul edilebilir boşluk \\
- Kök kanal dolgusu içinde gözle \\
görünür sadece bir boşluk
\end{tabular} & $\begin{array}{c}\text { YETERLİ } \\
\text { - Radyografik apeks ile guta- } \\
\text { perkanın sonlandığı nokta } \\
\text { arasında }(1-2 \mathrm{~mm}) \text { mesafe }\end{array}$ \\
\hline 2 & $\begin{array}{c}\text { MÜKEMMEL } \\
\text { - Guta-perka ile kök kanal duvarı } \\
\text { arasında mükemmel uyum } \\
\text { - Kök kanal dolgusu içinde hiç } \\
\text { boşluk yok } \\
\end{array}$ & $\begin{array}{c}\text { YETERLİ } \\
\text { - Radyografik apeks ile guta- } \\
\text { perkanın sonlandığı nokta } \\
\text { arasında }(1-2 \mathrm{~mm}) \text { mesafe }\end{array}$ \\
\hline 3 & $\begin{array}{c}\text { MÜKEMMEL } \\
\text { - Guta-perka ile kök kanal duvarı } \\
\text { arasında mükemmel uyum } \\
\text { - } \quad \text { Kök kanal dolgusu içinde hiç } \\
\text { boşluk yok }\end{array}$ & $\begin{array}{c}\text { MÜKEMMEL } \\
\text { - Radyografik apeks ile guta- } \\
\text { perkanın sonlandığı nokta } \\
\text { arasında }(0-1 \mathrm{~mm}) \text { mesafe }\end{array}$ \\
\hline
\end{tabular}

Çok köklü dişlerde puanlama en kötü kaliteyi gösteren kök kanalının dolgusuna göre yapıldı. Her bir kök kanalı, hem homojenite hem de apikal mesafeye göre ayrı ayrı; kötü, yeterli ve mükemmel olarak sınıflandırılarak karşılıkı olarak puanlandı. Değişik varyasyonlara göre RKP sisteminin uygulanışı Tablo $2^{\prime}$ te verilmiştir. Homojenitesi kötü olan kök kanal dolgusuna sahip dişlerin ileride sızdırma yapacağı düşünülerek apikal mesafeye bakılmaksızın başarısız kabul edilerek 0 puan verilmiştir. Homojenitesi yeterli olan 
(mükemmel olmayan) kök kanal dolgularının apikal mesafesi mükemmel olsa bile 1 puan verilmiştir ve yine başarısız kabul edilmiştir. Çalışmamızda; 2'den az puanlar başarısız, 2 ve üzeri puanlar başarılı olarak kabul edilmiştir.

Tablo 2. Değişik varyasyonlara göre RKP sisteminin uygulanışı.

\begin{tabular}{|c|c|c|}
\hline RKP & $\begin{array}{c}\text { Homojenite } \\
\text { (lateral kondensasyon) }\end{array}$ & Apikal mesafe \\
\hline $\mathbf{0}$ & KÖTÜ & KÖTÜ \\
& KÖTÜ & YETERLİ \\
& KÖTÜ & MÜKEMMEL \\
& YETERLİ & KÖTÜ \\
& MÜKEMMEL & KÖTÜ \\
& YETERLİ & YETERLİ \\
& YETERLİ & MÜKEMMEL \\
\hline $\mathbf{1}$ & MÜKEMMEL & YETERLİ \\
\hline $\mathbf{2}$ & MÜKEMMEL & MÜKEMMEL \\
\hline $\mathbf{3}$ & \multicolumn{2}{|c}{} \\
\hline
\end{tabular}

\section{İstatistik Yöntem}

Tüm istatistiksel analizler için SPSS statistics 25 software (IBM Corp, Chicago, ABD), kullanıldı. Grup sayısı iki olan bağımsız grupların nonparametrik verilerinin karşılaştırılmasında Mann-Whitney U Testi kullanıldı. Grup sayısı ikiden fazla olan bağımsız gruplarda (her gruptaki denek sayısı <30 olduğundan), nonparametrik verilerin karşılaştırılması için Kruskal-Wallis test (nonparametric ANOVA) ve Post-hoc test (Dunn's Multible Comparison test) kullanıldı. Metodlar arasındaki ilişki varlığını araştırmak amacıyla nonparametrik veriler için Spearman korelasyon analizi kullanıldı.

\section{BULGULAR}

Klasik ve modern yöntem kullanılarak tedavi edilen hastalara ait tüm dişlerin tedavi sonrası, RKP skorları arasında istatistiksel olarak anlamlı bir korelasyon yoktu (Spearman r: $-0.03617,95 \%$ güven aralığı 0.1634 to $0.09224, \mathrm{P}=0.5700$ ) (Tablo 3).

Kök kanal tedavi yöntemleri, RKP skorları açısından incelendiğinde; üst premolar, üst molar ve alt molar gruplarında klasik yönteme kıyasla modern yöntemde daha yüksek RKP skoru elde edildi (sırasıyla, üst premolar: $2.22 \pm 0.91$ ve $2.71 \pm 0.52 \mathrm{P}=0.0261$, üst molar: $2.09 \pm 1.05$ ve $2.61 \pm 0.65 \mathrm{P}=0.0061$, alt molar: $2.13 \pm 0.96$ ve $2.68 \pm 0.63 \mathrm{P}=0.0008$ ) (Tablo 1 ). Ancak üst anterior, alt anterior ve alt premolar gruplarında tedavi yöntemlerine göre RKP skorları arasında fark yoktu ( $P>0.05$ ) (Tablo 1). Diş gruplarına göre kök kanal tedavi yöntemleri karşılaştırıldığında RKP skorları açısından istatiksel olarak bir fark yoktu ( $P>0.05)$ (Tablo 1). Yani diş gruplarının klasik veya modern tedavi yönteminin etkinliğini arttırıcı veya azaltıcı rolü yoktu.
Tablo 3. Diş gruplarına ve kök kanal tedavi yöntemlerine göre RKP başarı skorlarının karşılaştıııması

\begin{tabular}{|c|c|c|c|c|}
\hline & Toplam & Klasik Yöntem & Modem Yöntem & $\begin{array}{c}\text { *p } \\
\text { Değerleri }\end{array}$ \\
\hline N / Kt女 (\%) & $501 / 441(\% 88)$ & $228 / 180(\% 79)$ & $273 / 261(\% 96)$ & - \\
\hline $\begin{array}{l}\text { Üst Anterior } \\
\text { n/Ktb }(\%)\end{array}$ & $42 / 40(\% 95)$ & $21 / 19 \% 90)$ & $21 / 21(\% 100)$ & - \\
\hline $\begin{array}{l}\text { n/ktb (\%) } \\
\text { Skor }\end{array}$ & $2.67 \pm 0.65 \quad 3(0-3)$ & $\begin{array}{r}2.52 \pm 0.81 \\
3)\end{array} \quad 3(0-$ & $2.81 \pm 0.40 \quad 3(2-3)$ & $b_{0.3632}$ \\
\hline $\begin{array}{r}\text { Üst Premolar } \\
\text { n/Ktb (\%) }\end{array}$ & $70 / 63(\% 90)$ & $32 / 26(\% 81)$ & $38 / 37(\% 97)$ & - \\
\hline Skor & $\begin{array}{c}2.49 \pm 0.76 \\
3)\end{array}$ & $\begin{array}{r}2.22 \pm 0.91 \\
3)\end{array} \quad 2(0-$ & $2.71 \pm 0.52 \quad 3(1-3)$ & $b_{0.0261 *}$ \\
\hline $\begin{array}{l}\text { Üst Molar } \\
\text { n/Ktb (\%) } \\
\text { Skor }\end{array}$ & $\begin{array}{c}137 / 117(\% 85) \\
2.39 \pm 0.88 \\
3(0-3)\end{array}$ & $\begin{array}{c}58 / 43(\% 74) \\
2.09 \pm 1.05 \\
2(0-3)\end{array}$ & $\begin{array}{c}79 / 74(\% 94) \\
2.61 \pm 0.65 \\
3(0-3)\end{array}$ & ${ }_{0.0061 *}$ \\
\hline $\begin{array}{l}\text { Alt Anterior } \\
\text { n/Ktb (\%) } \\
\text { skor }\end{array}$ & $\begin{array}{c}39 / 35(\% 90) \\
2.62 \pm 0.63 \\
3(1-3)\end{array}$ & $\begin{array}{c}19 / 16(\% 84) \\
2.47 \pm 0.77 \\
3(1-3)\end{array}$ & $\begin{array}{c}20 / 19(\% 95) \\
2.75 \pm 0.44 \\
3(1-3)\end{array}$ & $b_{0.3941}$ \\
\hline $\begin{array}{l}\text { Alt Premolar } \\
\text { n/Ktb (\%) }\end{array}$ & $79 / 72(\% 91)$ & $35 / 29(\% 83)$ & $44 / 43(\% 98)$ & - \\
\hline skor & $\begin{array}{c}2.63 \pm 0.62 \\
3(1-3)\end{array}$ & $\begin{array}{c}2.46 \pm 0.78 \\
3(1-3)\end{array}$ & $\begin{array}{c}2.77 \pm 0.42 \\
3(1-3)\end{array}$ & $b_{0.1535}$ \\
\hline $\begin{array}{l}\text { Alt Molar } \\
\text { n/Ktb (\%) }\end{array}$ & $134 / 114(\% 85)$ & $63 / 47(\% 75)$ & $71 / 67(\% 94)$ & - \\
\hline skor & $\begin{array}{c}2.42 \pm 0.84 \\
3(0-3)\end{array}$ & $\begin{array}{c}2.13 \pm 0.96 \\
2(0-3)\end{array}$ & $\begin{array}{c}2.68 \pm 0.63 \\
3(0-3)\end{array}$ & $50.0008 *$ \\
\hline P değeri & & 0.1964 & 0.7710 & \\
\hline
\end{tabular}

bann-Whitney Test, c Kruskal-Wallis Test (Nonparametric ANOVA). P değerleri diş grupları arasında istatistiksel olarak anlamlı farklılı̆ın olup olmadığını göstermektedir. * $\mathbf{P}$ değeri $<0.05$ ise anlamlı kabul edildi. Skorlar ortalama \pm standart sapma ve ortanca (min-max) olarak verilmiştir. Ktb: Kanal tedavisi başarısı

Modern yöntemde en yüksek başarı oranı üst anterior grubunda \%100 ile sağlanırken, alt ve üst molar gruplarında \%94 ile en düşük başarı sağlandı. Klasik yöntemde, en yüksek başarı üst anterior grupta $\% 90$ iken, üst molar (\%74) ve alt molar (\%75) gruplarında ise en düşük başarı oranı sağlandı. Klasik yöntemdeki başarı oranı \%79 iken, modern yöntemde bu oran \%96' ya yükseldi. Genel olarak her iki grubun ortak başarı oranı \%88 olmuştur. Her iki grupta da öğrencilerin apikal mesafeyi mükemmel bulmada (0-1 mm) (\% 91), mükemmel homojen dolguya (kök kanal dolgusu içinde hiç boşluk yok) (\% 84) kıyasla daha başarılı oldukları saptanmıştır.

\section{TARTIŞMA}

Güncellenen tedavi yaklaşımları ve modern endodontik teknolojideki gelişmelere bağlı olarak endodontik tedavinin başarısı da artmaktadır. Ancak bu durum tedavilerin başarıları konusunda herhangi bir garanti sağlamamaktadır. Endodontik tedaviler, kurallara uyularak yapılsa bile, tedavi sonrası problemler yaşanabilmektedir. ${ }^{15}$

Avrupa Endodonti Topluluğu (ESE) 2006 yönergesine uygun olarak apikal periodontitis bulunmayan dişlere uygulanan kök kanal tedavilerinin başarı olasılığı 92\%- 98\% arasında değişmektedir. Apikal periodontitis bulunan dişlere uygulanan kök kanal tedavisinin başarı oranı ise $\% 73$ ila $\% 90$ arasındadır. $^{2}$

Kök kanal dolgusunun kalitesi ile tedavi sonrasında gelişen apikal periodontitis arasında yakın bir ilişki olduğu bilinmektedir. ${ }^{5,8}$ Bizim çalışmamızda kanal 
dolgusun kalitesi radyografik olarak değerlendirilmiş olup kanal tedavisinin uzun dönem başarısı ve apikal periodontitisin iyileşmesi hakkında bilgi vermemektedir. Teknik olarak uygun ve kaliteli yapılmıs kanal dolgusunun kanal tedavisinin uzun dönem başarısına katkı sağlayan en önemli faktörlerden birisi olduğu bilinmektedir. ${ }^{16}$ Çalışmamız sonuçlarına göre modern tekniğin dolgu kalitesi geleneksel yöntemden daha yüksek çıkmışır. Modern teknik klinik başarıya katkı sağlayabilir. Bu konu ile ilgili ileri klinik çalışmalar yapılması gerekmektedir.

Kök kanal tedavisinin kalitesini radyografiler üzerinden değerlendiren çalışmalar mevcuttur. Haznedaroğlu ve ark. ${ }^{17}$ öğrencilerin yaptıkları 159 dişin kanal tedavi kalitesini \% 34'ünü yeterli bulmalarına rağmen, 2 yıl boyunca takip ettikleri çalışmalarında \% 90 oranında klinik başarı bildirmişlerdir.

Dammaschke ve ark. ${ }^{18}$ on yıl boyunca öğrencilerin yaptıkları kök kanal tedavili dişleri takip etmişler ve $\% 85$ başarı oranı bildirmişlerdir. Aynı çalışmada çalışmanın başında değerlendirdikleri kanal tedavilerin kalitesini \% 82'sinde yeterli bulmuşlardır.

Ceyhanlı ve ark. ${ }^{19}$ stajyer diş hekimleri tarafından paslanmaz çelik el eğeleri ve step-back tekniğine göre yapılan kök kanal dolgularının teknik kalitesini radyografik olarak değerlendirdikleri çalışmalarında \% 55.28 başarıı olarak tespit etmişlerdir. Benzer bir çalışmada, Yoldaş ve ark. ${ }^{20}$ ise $\% 66$ başarı oranı belirtmişlerdir. Fakat molar dişlerdeki kök kanal tedavisin kalitesinin diğer diş gruplarına göre daha düşük olduğunu bildirmişlerdir. Aynı teknikle bizim yaptığımız grupta bu oran \% 79 bulunmuştur. Aradaki farkın, bizde tedaviyi yapanların stajyer hekim yerine yüksek lisans mezunu hekimler olması ve endodonti üzerine doktora yapıyor olmalarından kaynaklandığını düşünmekteyiz. Yine bizim çalışmamızda da molar dişlerdeki başarı oranı diğer gruplara göre daha düşük bulunmuştur.

Kök kanal tedavilerinin kalitesinin radyografik olarak değerlendirilmesi birçok çalışmada lisans öğrencileri üzerinden yapılmış olup ${ }^{19-22}$, bizim çalışmamız gibi doktora öğrencilerine yönelik bir araştırma olmadığı için birebir sonuçlarımızı karşılaştırabilme fırsatımız olmamıştır. Çalışmamızın bu açıdan ilerde yapılacak doktora öğrencilerine yönelik araştırmalara katkı sağlayacağını düşünüyoruz.

Kök kanallarının genişletilmesi, uzun yıllar yaygın olarak step-back yöntemi kullanılarak paslanmaz çelik el eğeleri ile yapılmıştır. Endodonti uygulamaların da, kök kanal temizlenme ve şekillendirilmesinde bir tork kontrollü motor ile $\mathrm{Ni}$ - $\mathrm{Ti}$ döner aletlerin kullanılmaya başlanması devrim niteliğinde bir adım olmuştur. Bu yeni nesil Ni-Ti döner aletler paslanmaz çelik el eğelerine göre daha esnektirler ve daha az kanal transportasyonu ve çalışma uzunluğu kaybına neden olurlar. ${ }^{23,24}$ El ile kullanılan paslanmaz çelik eğelerle şekillendirme yapılan kök kanal tedavilerinin $\mathrm{Ni}-\mathrm{Ti}$ enstrümanlarla yapılanlara kıyasla daha fazla prosedürel hata ve daha düşük başarı oranı sergilediği gösterilmiştir. 25,26

$\mathrm{Ni}-\mathrm{Ti}$ döner alet sistemlerinin, avantajlarının yanısıra bazı dezavantajlarının da olması, yeni arayışları beraberinde getirmiştir ve resiprokal hareket ile çalışan sistemler geliştirilmiştir. Bu sistemler; kolay ve pratik kullanımları, çapraz enfeksiyon riskini azaltması, kırımaya karşı daha dirençli olmaları ve etkili şekillendirme yapmaları dolayısıyla daha çok tercih edilir hale gelmişlerdir. ${ }^{27}$ Ayrıca resiprok eğelerin diğer Ni-Ti eğelere kıyasla kırımaya karşı daha dirençli oldukları ve daha başarılı kök kanal şekillendirmesi yaptıklarını gösteren çalışmalarda mevcuttur. ${ }^{28,29}$ Bu çalışmamızda da paslanmaz çelik el eğeleri ile yapılan preparasyon grubu resiprok aletlerle yapılanlara göre daha başarısız çıkmıştır. Her iki grupta da öğrencilerin apikal mesafeyi mükemmel bulma konusunda, mükemmel homojen dolguya kıyasla daha başarılı olmalarını, iki grupta da apekslokatör kullanılmasına bağlı olduğunu düşünmekteyiz.

Lateral kondensasyon yöntemi yıllardır kök kanallarının doldurulmasında kullanılan en yaygın yöntemdir. Döner Ni-Ti eğeler ile uyumlu olan tek kon açılı güta-perka yöntemi, kanalın şekli enine kesitte dairesel veya tam yuvarlak olduğunda ana konun kanala tam olarak yerleştirildiği yöntemdir. ${ }^{30} \mathrm{Klasik}$ dolum yöntemlerinden daha kısa sürede kanal dolgusu yapılmasına olanak sağlamaktadır. Bizde çalışmamızda lateral kondensasyon ve tek kon yöntemi arasındaki metotsal farklılığı en az seviyeye indirmek için dairesel olmayan kanallarda tek kon tekniğini lateral kondensasyon ile birlikte kullandık.

Kök kanal sisteminin anatomisi, başarılı bir kök kanal tedavisine yapmak için değerlendirilmesi gereken ana etkendir. İstenilen şekil, kök kanalının enine kesit çapının kök apeksine doğru kademeli olarak azaltılmasıyla elde edilir. ${ }^{31} \%$ 4'ün üzerinde bir konikliğe sahip döner aletlerin, kök kanallarının şekillendirilmesinde el eğelerinden daha başarılı olduğu gösterilmiştir. ${ }^{32}$ Aynı zamanda kanal şekillendirilmesinde oluşturulan artan taper varlığının kanal dolgusunun başarısında önemli bir rol oynadığı bildirilmiştir. 33,34 
Bizim çalışmamızda da \% 6 taper'a sahip resiprok eğelerin kullanıldığı modern yöntemin daha başarıı sonuçlar vermeside bu görüşü desteklemektedir.

RKP, daha önce yapılmış olan çalışmalarla benzer kriterleri içermektedir. ${ }^{19,20}$ Fakat bu çalışmalarda kanaIın homojenliğinin iyi olduğu ve apikal mesafenin 0-2 $\mathrm{mm}$ arası olduğu kök kanal dolguları başarıı kabul edilirken bizim çalışmamızda ise homojenitesi mükemmel olan ve aynı zamanda daha ideal apikal mesafe olan 0-1 mm başarılı kabul edilerek en yüksek RKP skoru olan 3 puan verilerek en kaliteli kök kanal dolgusu olarak belirlenmiştir. Radyografik apeks ile fizyolojik apeks her zaman örtüşmemektedir. Son yıllarda yapılan çalışmalarda kök kanal tedavisinin ideal sonlanma noktasının radyografik apeksten $0-1 \mathrm{~mm}$ geride olduğunu göstermiştir. ${ }^{14,35}$

Değerlendirmemiz periapikal röntgen filmleri üzerinden iki boyutlu olarak yapılmışıı. Üçüncü boyuttaki kanal dolgu homojenitesi ve kalitesi ancak bilgisayarlı tomografiler üzerinden değerlendirilebilmektedir. Son zamanlarda ekstraoral üç boyutlu görüntüleme tekniği olan Konik Işınlı Bilgisayarlı Tomografi bu konuda başarılı sonuçlar vermektedir. Fakat periapikal röntgenlere göre daha fazla radyasyon içermekte ve henüz her vakada rutin kullanımı yaygın değildir ve tartışmalıdır. ${ }^{11}$

\section{SONUC}

Sağlık Bilimleri Üniversitesi, Hamidiye Diş Hekimliği Fakültesi, Endodonti Anabilim Dalı doktora öğrencisi hekimler tarafından, klasik ve modern yöntemle yapılan kök kanal tedavilerinin kalitesinin radyografik olarak değerlendirilmesi sonucunda, klasik yöntemde $\% 79$, modern yöntemde $\% 96$ ve genel olarak \% 88 başarı oranı elde edilmiştir. Döner aletlerle yapılan kök kanal tedavilerinin radyografik kalitesi, paslanmaz çelik el eğeleri ile yapılanlara göre daha başarıı bulunmuştur. En düşük başarı oranlarının elde edildiği molar dişlerdeki tedavi başarısının artıııması için bu dişlere yönelik eğitim ve uygulamalara ağırlık verilmesi gerekmektedir.

\section{TESEKKÜR}

İstatiksel analizlerdeki katkılarından dolayı Doç. Dr. Fatih Özçelik'e ve Endodonti $A D$. doktora öğrencileri; Dt. Naciye Atcı Hazar, Dt. Serkan Duran, Dt. Duygu Çakır ve Dt. Umut Nihat Gözen'e teşekkür ederim. Finansal Destek

Yazarl/yazarlar bu çalışma için finansal destek almadıklarını beyan etmişlerdir.

\section{KAYNAKLAR}

1. Nguyen NT. Obturation of the root canal system. İn: Cohen S, Burns RC, eds. Pathways of the pulp. $6^{\text {th }}$ ed. St. Louis; CV Mosby: 1998. p. 219-71.

2. European Society of Endodontology. Quality guidelines for endodontic treatment: consensus report of the European Society of Endodontology. Int Endod J 2006;39:921-30.

3. Chandra BS, Gopıkrıshna V. Obturation of Radicular Space. Grossmans Endodontic Practice. $12^{\text {th }}$ ed. New Delhi; Wolters kluwer: 2013. p. 278-300.

4. Petersson K, Petersson A, Olsson B, Hakansson J, Wennberg A. Technical quality of root fillings in an adult Swedish population. Endod Dent Traumatol 1986;2:99-102.

5. De Moor RJ, Hommez GM, De Boever JG, Delme KI, Martens GE. Periapical health related to the quality of root canal treatment in a Belgian population. Int Endod J 2000;33:113-20.

6. Boltacz-Rzepkowska E, Pawlicka H. Radiographic features and outcome of root canal treatment carried out in the Lodz region of Poland. Int Endod J 2003;36:27-32.

7. İlgüy $D$, İlgüy $M$, Fişekçioğlu $E$, Ersan N, Tanalp J, Dölekoğlu S. Assessment of root canal treatment outcomes performed by turkish dental students: results after two years. J Dent Ed 2013;77:502-50.

8. Kabak Y, Abbott PV. Prevalence of apical periodontitis and the quality of endodontic treatment in an adult Belarusian population. Int Endod J 2005;38:238-45.

9. Burke FM, Lynch $C D$, Ní Ríordáin R, Hannigan A. Technical quality of root canal fillings performed in a dental school and the associated retention of root-filled teeth: a clinical follow-up study over a 5year period. J Oral Rehabil 2009;36:508-15.

10. Bhatt M, Coil J, Chehroudi B, Esteves A, Aleksejuniene J, MacDonald D. Clinical decisionmaking and importance of the AAE/AAOMR position statement for $\mathrm{CBCT}$ examination in endodontic cases. Int End J 2021;54:26-37.

11. MacDonald D. Cone-beam computed tomography. In: D MacDonald, ed. Oral and Maxillofacial radiology: A Diagnostic Approach, $2^{\text {nd }}$ ed. New jersey: Wiley Blackwell: 2020. p. 97- 100.

12. Hommez GM, Coppens CR, De Moor RJ. Periapical health related to the quality of coronal restorations and root fillings. Int Endod J 2002;35:680-89.

13. Buckley M, Spangberg LSW. The prevalence and technical quality of endodontic treatment in an American subpopulation. Oral Surg Oral Med Oral Pathol Oral Radiol Endod 1995;79:92-100.

14. Mothanna K. AlRahabi. [Technical quality assessment of root canal treatment performed by 
preclinical dental students at Taibah University]. KSA J Taibah Univ Med Sci. 2017; 12:27-33.

15. Bradford R, Johnson BR, Fayad MI, Witherspoon DE. Periradicular Surgery. In: Hargreaves KM, Cohen S, Berman LH eds. Cohen's pathways of the pulp. $10^{\text {th }}$ ed. St. Louis; Mosby Elsevier: 2011. p. 720-76.

16. Dugas NN, Lawrence HP, Jeplitsky PE, Pharoah MJ. Periapical health and treatment quality assessment of root-filled teeth in two Canadian populations. Int Endod J 2003;36: 181-92.

17. Haznedaroğlu F, Dulger J, Ersev H, Dişci R, Şirin Ş. Endodonlik tedavilerde başarı oranının istatistiksel olarak değerlendirilmesi. Dişhek Derg 1995;4:3641.

18. Dammaschke T, Steven D, Kaup M, Ott KH. Longterm survival of root-canal-treated teeth: a retrospective study over 10 years. J Endodon 2003;29:638-43.

19. Ceyhanlı KT, Çelik D, Çıkman A, Taşdemir T. Stajyer diş hekimleri tarafından yapılan kök kanal dolgularının teknik kalitesinin radyografik olarak değerlendirilmesi. EÜ Dişhek Fak Derg 2015;36:2531.

20. Yoldaş O, Oztunc H, Topuz A, İşci AŞ. 4. Sınıf ve 5. Sınıf dişhekimliği öğrencileri tarafından yapılan kanal tedavilerinin kalitesinin radyolojik değerlendirilmesi. Ondokuz Mayis Univ Dis Hek Fak Deıg 2004;5:65-68.

21. Lynch CD, Burke FM. Quality of root canal fillings performed by undergraduate dental students on single-rooted teeth. Eur J Dent Ed 2006;10:67-72.

22. Gound TG, Sather JP, Kong TS, Makkawy HA, Marx DB. Graduating dental students' ability to produce quality root canal fillings using single or multiple cone obturation techniques. J Dent Educ 2009; 73: 696-705.

23. Çelik D., Taşdemir T., Er K. Comparative study of 6 rotary nickel-titanium systems and hand instrumentation for root canal preparation in severely curved root canals of extracted teeth. J Endod 2013;2:278-282.

24. Nakagawa R., Alves J., Buono V., Bahia M. Flexibility and torsional behaviour of rotary nickeltitanium PathFile, RaCe ISO 10, Scout RaCe and stainless steel K-File hand instruments. Int Endod J 2014; 1:290-7.

25. Cheung GS, Liu CS. A retrospective study of endodontic treatment outcome between nickeltitanium rotary and stainless steel hand filing techniques. J Endod 2009;35: 938-43.
26. Garip G, Nur BG, Altunsoy M, Ok E. Süt dişlerinde nikel titanyum döner aletlerinin kullanımının değerlendirilmesi. Atatürk Üniv Diş Hek Fak Derg 2016; 25.

27. Gökyay S, Çalışkan E. Endodontic systems working with reciprocal movements for instrumentation of root canals. Aydın Dental 2015; 1: 51-60.

28. Adıgüzel $M$, Tüfekçi $P$. Waveone, recıproc ve twısted file adaptıve döner sistem eğelerin çift kurvatürlü (s-şekilli) kanallarda döngüsel yorulma dirençlerinin karşılaştırılması. Atatürk Üniv Diş Hek Fak Derg 2018; 28: 199-203.

29. Koçak MM, Koçak S, Türker SA, Sağlam BC. Cleaning efficacy of reciprocal and rotary systems in the removal of root canal filling material. J Conserv Dent 2016;19:184-8.

30. Çapar İD, Ertas H, Gök T. Farklı dolum teknikleri ile doldurulan kök kanallarından kanal dolgu malzemesinin uzaklaştırımasının değerlendirilmesi. SDÜ Sağlık Bil Derg 2014; 5: 51-5.

31. Ruddle $\mathrm{CJ}$. Cleaning and shaping the root canal system, in Pathway of the pulp, S.Cohen, RC Burns. $8^{\text {th }}$ ed. St. Louis; CV Mosby: 2002. p. 241-5.

32. El Ayouti A, Chu AL, Kimionis I, Klein C, Weiger R, Löst C. Efficacy of rotary instruments with greater taper in preparing oval root canals. Int Endod J 2008;41:1088-92.

33. Zogheib C, Hanna M, Pasqualini D, Naaman A. Quantitative volumetric analysis of cross-linked gutta-percha obturators. Ann Stomatol 2016;7:4651.

34. Ozkocak I, Sonat B. Evaluation of effects on the adhesion of various root canal sealers after Er:YAG Laser and irrigants are used on the dentin surface. J Endod 2015;41: 1331-6.

35. Naito $T$. Better success rate for root canal therapy when treatment includes obturation short of the apex. Evid Based Dent 2005;6:45.

\section{Sorumlu Yazarın Yazışma Adresi}

Dr. Öğr. Üyesi Dursun Ali şi̇í̃N

Sağılık Bilimleri Üniversitesi, Hamidiye Diş

Hekimliği Fakültesi Endodondi AD. Selimiye

Mah. Tıbbiye cad. Üsküdar/ İSTANBUL

Tel: +902165422020 Fax: +902165422021

E-Mail: dtalisirin@gmail.com 